\title{
Insecticide susceptibility of the green plant bug, Apolygus lucorum Meyer-Dür (Homoptera: Miridae) and two predatory arthropods
}

\author{
Zhengqun Zhang ${ }^{1,2}$, Xuefeng Zhang', Feng Liu' ${ }^{1}$ Wei Mü* \\ ${ }^{1}$ College of Plant Protection, Shandong Agricultural University, Tai'an 271018, China \\ ${ }^{2}$ College of Horticulture Science and Engineering, Shandong Agricultural University, Tai'an 271018, China
}

Received: May 27, 2015

Accepted: October 15, 2015

\begin{abstract}
The green plant bug (Apolygus lucorum Meyer-Dür) is a key pest of Bt cotton in China. Along with biological control, chemical control is one of the most important strategies in A. lucorum Integrated Pest Management (IPM). The goal of this study was to evaluate the toxicity of eight conventional insecticides to A. lucorum and to assess the susceptibility of two generalist predators Chrysopa sinica (Jieder) and Propylaea japonica (Thunbery) to insecticides that are commonly used in A. lucorum management. Via glass-vial and leaf-dip bioassay, toxicity tests with selected insecticides at two different life-stages of A. lucorum indicated significant differences between the $\mathrm{LD}_{50}$ or $\mathrm{LC}_{50}$ values for these compounds within different insecticidal classes. Phenylpyrazole fipronil had the highest toxicity to 4th-instar nymphs and adults of A. lucorum, whereas neonicotinoid imidacloprid had the lowest toxicity among the insecticides. Females were more tolerant to insecticides than were males, as shown by the higher $\mathrm{LD}_{50}$ values for females. Furthermore, laboratory tests showed that endosulfan had the highest selectivity to C. sinica and P. japonica: the selective toxicity ratios (STRs) were superior to other tested insecticides, particularly imidacloprid, and were 5.396 and 4.749-fold higher than baseline STRs, respectively. From this study, we conclude that fipronil can potentially be used to efficiently control A. lucorum. An alternative control agent worth consideration is endosulfan, owing to its relative safety to non-targeted natural enemies.
\end{abstract}

Key words: Apolygus lucorum, Chrysopa sinica, Propylaea japonica, safety evaluation, toxicity

\section{Introduction}

Plant bugs (Homoptera: Miridae) occur worldwide and are one of the most destructive pests of cotton (Gossypium hirsutum L.) (Wheeler 2001). Since the widespread cultivation of Bt cotton in the Yellow River and Yangtze River valleys of eastern and southern China, cotton crops have suffered seriously from green plant bug (Apolygus lucorum Meyer-Dür) attacks while greatly reducing insecticide use for the control of Helicoverpa armigera (Hübner) (Wu 2007; Wu et al. 2008; Lu et al. 2012a; Lu et al. 2013). Feeding by A. lucorum adults and nymphs results in bud blast, flower abortion, and missing or shrunken squares and bolls. These abnormalities arise primarily from the activity of polygalacturonase in the salivary glands of A. lucorum, and cause extremely large cotton yield losses of up to 20-30\% (Lu et al. 2007; Zhang et al. 2013). This pestiferous bug of Bt cotton also feeds on other perennial crops (e.g. beans, the Chinese date, the tea plant, cherry, apple, and peach), specifically at the flowering stage in the major Chinese cotton-growing regions (Lu et al. 2012b; Pan et al. 2013; Zhang et al. 2013). High-density outbreaks of A. lucorum frequently occur in cotton fields ( $\mathrm{Lu}$ et al. 2010, 2011). Lu et al. (2008a, 2010) reported that A. lucorum infection levels were 10 per 100 plants at the seedling stage, and its peak density ranged from 50 to 200 per 100 plants during the squaring and flowering stages. If the published economic thresholds for A. lucorum (seedling stage: 5 bugs $\cdot 100^{-1}$ plants; mid-period of cotton growth: 10 bugs $\cdot 100^{-1}$ plants) proposed by Zhang et al. (1986) had been followed, the need to control A. lucorum in Bt cotton fields would have been urgent based on the data of $\mathrm{Lu}$ et al. (2008a, 2010). Hence, suitable techniques for managing A. lucorum populations on Bt cotton are needed.

One of the important strategies used in the Integrated Pest Management (IPM) of A. lucorum is chemical control. The pest's numbers are often kept below the economic threshold with the use of chemicals. Currently, chemical insecticides are the most accessible control option to Chinese cotton growers, primarily because chemical insecticides are effective, easy to operate, cost-effective, and reliable against the target pests (Zhao 2000; Tan et al. 2012). Few alternative control measures are available (Hardee and Bryan 1997; Wu 2007). Wu et al. (2002) have confirmed that the population density of A. lucorum in chemically-controlled plots was far lower than that in non-chemically controlled plots. Traditionally, more than four broad-spectrum insecticide applications for A. lucorum are administered every growing season with 
organophosphates, carbamates, synthetic pyrethroids, and a few organochlorines (e.g. endosulfan) being the most common insecticides in various agricultural areas of China (e.g. Shandong which is a major province of cotton agriculture) (Zhang et al. 2009; Guo et al. 2010). In addition, neonicotinoids, the dominant insecticidal classes, are widely used as foliar sprays and seed treatments against piercing-sucking pests of Bt cotton (Kumar et al. 2012; Tan et al. 2012). So far, most cotton growers also frequently choose neonicotinoids to control A. lucorum in China (Liu et al. 2007). As a well-known insecticide with a novel mechanism of action, fipronil has been shown to be highly effective against a broad range of economically important insect pests in agriculture, including sucking pests in cotton (Zhao and Salgado 2010; Kumar et al. 2012; Shi et al. 2012; Ahmed et al. 2015). The aforementioned chemicals were used in the present research to assess their toxicity to A. lucorum.

Although insecticide treatments may be substantial at present, natural predators in Bt cotton fields are an additional and necessary source of biological control for $A$. lucorum populations. The integration of chemical and biological control is key for the success of the IPM program (Planes et al. 2013; Saber and Abedi 2013). Insecticides provide effective control of key pests, but at the same time these insecticides often have adverse impacts on other beneficial organisms (Kumar et al. 2012; Moens et al. 2012). In Chinese Bt cotton-planting regions, the most common generalist predators are Chrysoperla sinica (Jieder) and Propylaea japonica (Thunbery). These predators are the most consistently abundant. They attack A. lucorum and several other pests, such as aphids, thrips, mites and whitefly, at all developmental stages (Deng et al. 2003). Currently, little is known about the toxicity of chemical insecticides used in Bt cotton on these two predatory species. Therefore, knowledge of the selective toxicity of the chemicals on predators and A. lucorum is crucial. Environmentally sound, less hazardous and sustainable chemicals for the control of A. lucorum are urgently needed.

The objectives of our study were to: assess the efficacy of eight common insecticides to A. lucorum, establish baselines, and further determine whether the susceptibility of females was different from that of males with regard to selected insecticides. Specifically, the latter laboratory assay was focused on the selective toxicity of these insecticides to $C$. sinica and P. japonica to assess the potential compatibility of biological and chemical control for improved IPM programs of A. lucorum. Overall, our aims are to supply accurate information to cotton growers for the rational application of insecticides in the chemical control of A. lucorum, and to reduce pesticide use in Bt cotton-planting regions.

\section{Materials and Methods}

\section{Test insects}

Apolygus lucorum adults were obtained from established laboratory colonies collected from a Xiajin County cotton field $\left(36^{\circ} 55^{\prime} 30^{\prime \prime} \mathrm{N}, 115^{\circ} 56^{\prime} 59^{\prime \prime} \mathrm{E}\right)$ in Shandong Province, China. Sweep nets were used to catch the A. lucorum adults from the fields, from July to October, 2009. The population colony was maintained on fresh asparagus bean pods (Phaseolus vulgaris L.) under consistant laboratory conditions of $25^{\circ} \mathrm{C}, 70 \%$ relative humidity $(\mathrm{RH})$ and a photoperiod of $14: 10$ (L:D) h, as described in Lu et al. (2008b) and Feng et al. (2012). Eggs laid in asparagus bean pods were placed in plastic insect boxes $(23 \times$ $\times 15 \times 9 \mathrm{~cm}$ ) along with moist paper, until the eggs hatched. The nymphs and subsequent adults were reared with the asparagus bean pods in the controlled environment of the laboratory. The bean pods were washed in detergent and soaked in a $0.5 \%$ sodium hypochlorite solution as described in Snodgrass (1996). This procedure was done to remove or oxidize any insecticide residue on them in advance. Pods were replaced every 2 days and those containing A. lucorum eggs were transferred to a new rearing box to initiate a new generation. Supplementary nutrition consisted of a $10 \%$ honey solution on water-soaked piece of cotton which was changed daily.

Chrysoperla sinica and P. japonica adults were obtained from laboratory colonies that were established with the eggs of insects collected from the experimental cotton field and nearby corn field in the 2000s in Xiajin (Shandong), China. Newly hatched larvae were maintained in plastic containers $(3 \times 15 \times 9 \mathrm{~cm})$ with laboratory reared cotton aphids (Aphis gossypii Glover) until eclosion and were then transferred to wooden cages $(50 \times 50 \times 50 \mathrm{~cm})$ fitted with four fine nylon mesh screens for maintenance at $25^{\circ} \mathrm{C}$ with $70 \% \mathrm{RH}$ and a $14: 10$ (L : D) h photoperiod. All predators were reared under insecticide-free conditions until the desired developmental testing stages.

\section{Insecticides}

The technical grade insecticides with a purity higher than 95\% used in the bioassays were: $95 \%$ endosulfan (organochlorine) (Makhteshim-Agan Industries Ltd., Shanghai, China), 98\% bifenthrin (synthetic pyrethroid) (Yangnong Chemical Co., Ltd., Jiangsu, China), 97\% chlorpyrifos (organophosphate) (Dow AgroSciences LLC., Indianapolis, IN, USA), 95\% malathion (organophosphate) (Sinochem Ningbo Chemical Co., Ltd., Zhejiang, China), 98\% methomyl (carbamate) (Changlong Chemicals Co., Ltd., Jiangsu, China), 95\% carbosulfan (carbamate) (Luba Chemicals Co., Ltd., Shandong, China), 96\% fipronil (phenylpyrazole) (Bayer CropScience Ltd., Zhejiang, China), and 96.8\% imidacloprid (neonicotinoid) (Hisun Chemical Co., Lid., Zhejiang, China). For contact bioassays, the insecticides were used directly after being dissolved in acetone. In leaf-dip bioassays, an emulsible concentrate was prepared by dissolving each insecticide in a $1: 9$ mixture of Tween-80 (Jiangsu Hai'an Petrochemical Plant, Nantong, China)/acetone used as the solvent. The emulsifier Tween- 80 in the solvent was used to avoid the precipitation of solutions after a period of time.

\section{Toxicity determination for Apolygus lucorum via glass- -vial bioassay}

A standard glass-vial bioassay (Snodgrass and Scott 2000; Zhang et al. 2009) was used to determine the toxicity of insecticides to A. lucorum nymphs and adults. Five to 
eight concentrations within a mortality range of $0-100 \%$ based on preliminary assays, were prepared from serial dilutions as $\mathrm{mg} \cdot \mathrm{l}^{-1}$ of the active ingredient of the test compounds with acetone before treatment. Each insecticide was applied by pipetting $0.5 \mathrm{ml}$ of the insecticide dissolved in $99.7 \%(\mathrm{v} / \mathrm{v})$ acetone, into $20-\mathrm{ml}$ glass scintillation vials $\left(2.8 \mathrm{~cm}\right.$ diameter, $6.1 \mathrm{~cm}$ high, $59.786 \mathrm{~cm}^{2}$ inner area). Then, the treated vial was manually rotated until no more droplets were seen on the glass wall. At this point, the vial was kept at room temperature for $1 \mathrm{~h}$ to allow for the complete evaporation of the acetone before introducing A. lucorum. Vials in the control treatments received only $0.5 \mathrm{ml}$ of acetone. A small piece of washed and sterilised asparagus bean pod (cut transversely, $3 \mathrm{~mm}$ thick) was added to each vial as food for A. lucorum. Next, five 4th-instar nymphs or active adults which were 2-4 days old were transferred into one vial, and the vial was then sealed by one layer of gauze to allow for air circulation. Three replications of $10 \mathrm{~A}$. lucorum per concentration were conducted in each insecticide treatment. After the treatment, the vials were held during the test in an upright position under environmental conditions necessary for rearing hemipterans. Mortality was checked after $24 \mathrm{~h}$ by counting the number of surviving bugs. The tested insects were considered dead if they were unable to stand normally or walk, or there was no movement when disturbed with a fine needle.

\section{Toxicity determination for Apolygus lucorum via leaf- -dip bioassay}

The leaf-dip method was adopted for the ingestion bioassay to evaluate the stomach toxicity in A. lucorum. Five to eight concentrations within a mortality range of $0-100 \%$ based on preliminary assays were prepared from serial dilutions using $0.1 \%(\mathrm{v} / \mathrm{v})$ Tween-80 in distilled water. Fresh and uncontaminated top leaves of cotton (cut to a square area of $2 \times 2 \mathrm{~cm}$ ) with approximately $2 \mathrm{~cm}$ of petiole were individually dipped into one of the solutions for $5 \mathrm{sec}$, removed, and dried for $2 \mathrm{~h}$ in the open air on filter paper. One treated leaf was inserted into $1 \%$ agar medium (ca. $1 \mathrm{ml})$ at the bottom of a tube $(2.5 \mathrm{~cm}$ diameter, $8 \mathrm{~cm}$ high) to maintain moisture. Five 4 th-instar nymphs or active adults which were $2-4$ days old were introduced into each tube, and the tube was then sealed by one layer of gauze. Three replications of 10 individuals per concentration were conducted in each insecticide treatment. After the treatment, the tubes were kept in an upright position under the environmental conditions outlined for rearing hemipterans. Mortality was recorded after $48 \mathrm{~h}$. Cotton leaves were dipped into $0.1 \%$ (v/v) Tween-80 in distilled water as an untreated control.

\section{Toxicity determination for Chrysopa sinica and Propylacea japonica}

The bioassay that was developed to determine the toxicity for two predators was modified from that of Xue and Li (2002), in which the test procedures were similar to those described above as the glass-vial bioassay applied in the toxicity determination for A. lucorum. Each vial contained two active adult $C$. sinica or $P$. japonica which were $1-2$ days old. Each vial was kept at a constant temperature of $25^{\circ} \mathrm{C}$ with $70 \% \mathrm{RH}$ and an $14: 10$ (L : D) h photoperiod. Three replications of $10 \mathrm{C}$. sinica or $P$. japonica adults per concentration were conducted in each insecticide treatment. Mortality was assessed at $24 \mathrm{~h}$ after treatment.

\section{Data analysis}

Data were corrected for the control mortality using Abbott's (1925) formula before analysis. For each insecticide, regression lines, $\mathrm{LD}_{50}$ or $\mathrm{LC}_{50}$ values, $\chi^{2}$ values, and $95 \%$ confidence limits were calculated using the Probit procedure in SAS/STAT version 9.2. The $\mathrm{LD}_{50}$ or $\mathrm{LC}_{50}$ values without overlapping 95\% confidence limits are considered to be significantly different $(\mathrm{p}<0.05)$.

\section{Results}

\section{Toxicity of insecticides determined by the glass-vial bioassay}

The toxicity of eight insecticides to 4th-instar nymphs and adults were investigated by the glass-vial bioassay to elucidate the contact toxicities of the tested compounds to the different life stages of A. lucorum. The slopes of the probit lines varied but were relatively steep in all cases, indicating a homogenous population response within each chemical. The three most toxic compounds for the 4th-instar nymphs were fipronil, bifenthrin, and chlorpyrifos, with $\mathrm{LD}_{50}$ values of $0.107,0.125$, and $0.251 \mathrm{mg} \cdot \mathrm{m}^{-2}$, respectively. Among eight tested insecticides, fipronil with an $\mathrm{LD}_{50}$ of $0.013 \mathrm{mg} \cdot \mathrm{m}^{-2}$ was the compound most toxic to adults. The next most toxic insecticides were bifenthrin and methomyl with $\mathrm{LD}_{50}$ values of 0.132 and $0.196 \mathrm{mg} \cdot \mathrm{m}^{-2}$, respectively. The $\mathrm{LD}_{50}$ value for imidacloprid was the lowest and was significantly different from all the other seven $\mathrm{LD}_{50}$ values. Based on the non-overlapping confidence limits of $\mathrm{LD}_{50}$ values, slight but significant differences in susceptibility were observed among the eight tested insecticides. Fipronil was most toxic to the different life stages of $A$. lucorum. The relative toxicity indices for fipronil were 0.002 and 0.001 , respectively, when we used the $\mathrm{LD}_{50}$ values for imidacloprid, the least toxic insecticide to A. lucorum (Table 1).

\section{Toxicity of insecticides determined by the leaf-dip method}

For A. lucorum nymphs and adults, the dosage mortality equations for the eight insecticides tested by the leaf-dip method for $48 \mathrm{~h}$ responses, are summarised in table 2 . From all the compounds for the 4th-instar nymphs, fipronil, with an $\mathrm{LC}_{50}$ of $0.153 \mathrm{mg} \cdot \mathrm{l}^{-1}$, was the most toxic insecticide to A. lucorum, and was significantly different in its toxicity from all other compounds tested. Bifenthrin was the second most toxic insecticide to nymphs, with an $\mathrm{LC}_{50}$ of $6.304 \mathrm{mg} \cdot \mathrm{l}^{-1}$. Methomyl and imidacloprid had $\mathrm{LC}_{50}$ values of 695.854 and $895.416 \mathrm{mg} \cdot \mathrm{l}^{-1}$, respectively, and were the least toxic and they were not significantly different from each other. For A. lucorum adults, the ranking of the 
(3)

(2)

是

(อ)

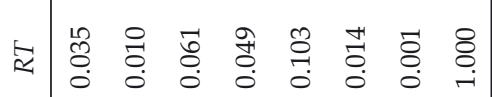

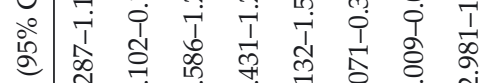

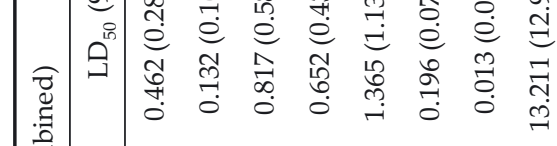

荧

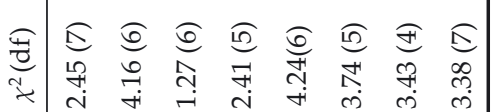

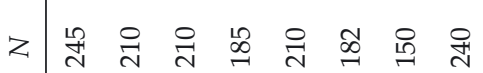

1

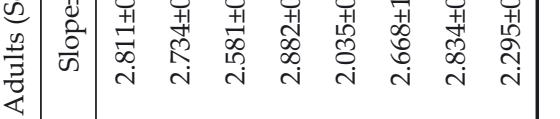
? .

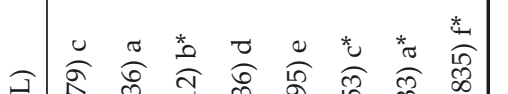

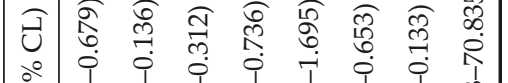

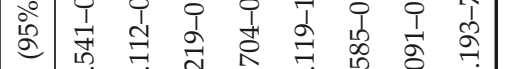

月

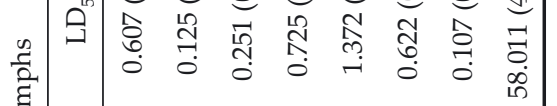

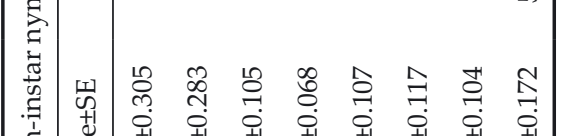

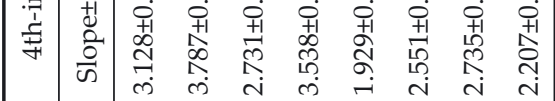

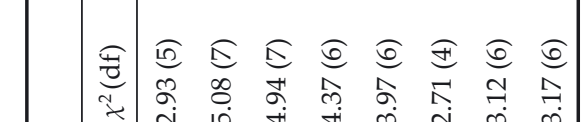

(1)

ह

ฉ

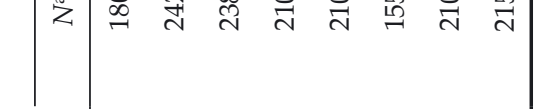

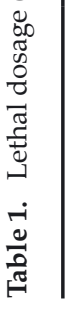

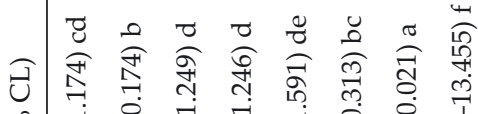

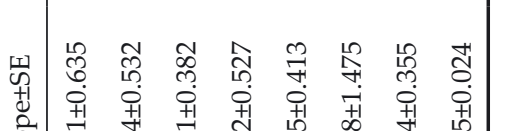

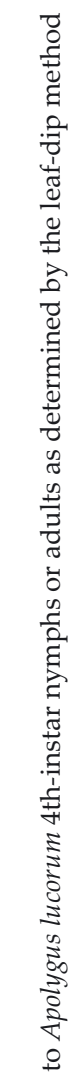

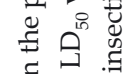

额

च

苟 :

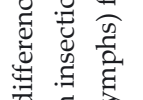

节

苛

क त

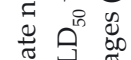

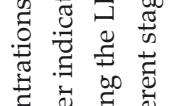

ठ

유류 छี

๘

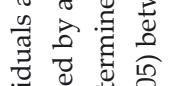

$\begin{array}{ccc}0 & 0 \\ 0 & 0 & 0 \\ 0 & 0 \\ 0 & 0 & 0 \\ 0 & 0 & 0 \\ 0 & 0 & 0\end{array}$ 引일

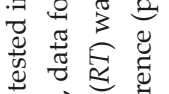

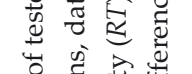

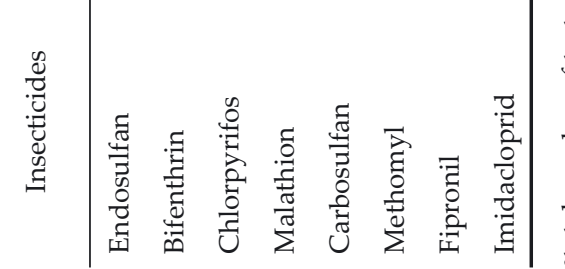
I

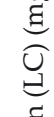

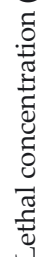

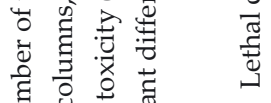
हี

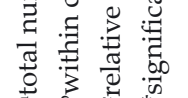

预

卷壱

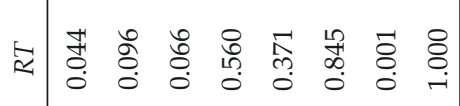

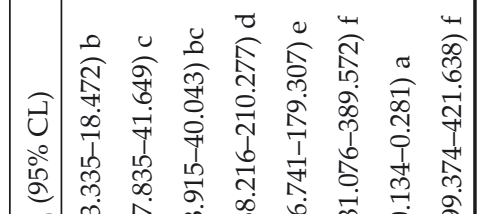

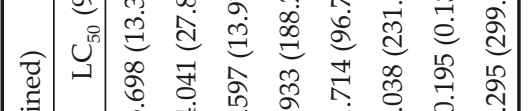
हี

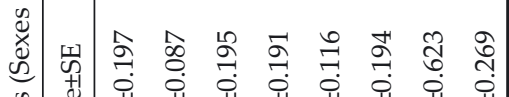

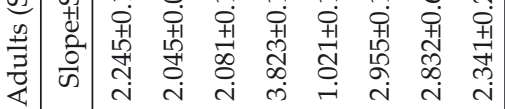

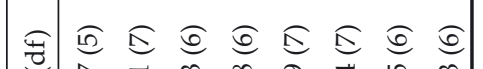
t)

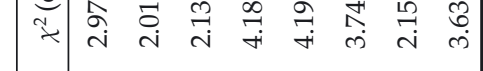

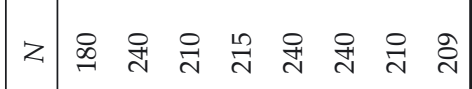

䒘

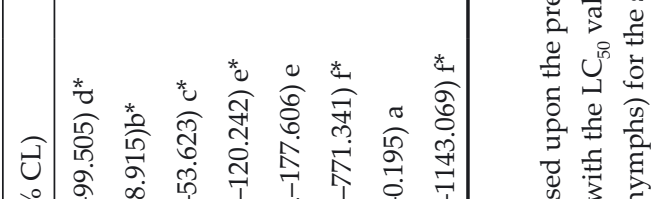

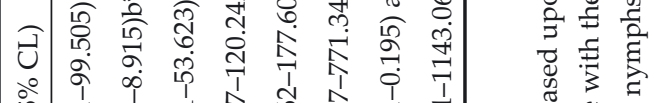

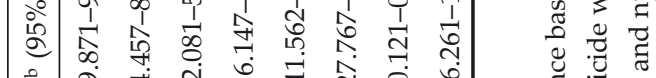

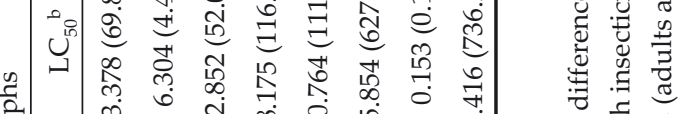

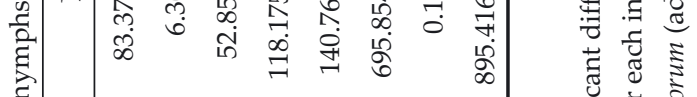

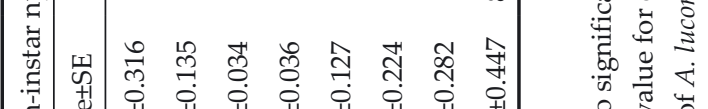

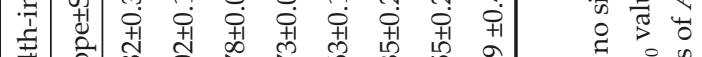

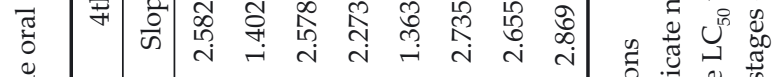


insecticides from most toxic to least toxic was: fipronil, endosulfan, chlorpyrifos, bifenthrin, carbosulfan, malathion, methomyl, and imidacloprid. For fipronil, the $\mathrm{LC}_{50}$ value of $0.195 \mathrm{mg} \cdot \mathrm{1}^{-1}$ indicated that it was the most toxic insecticide to the adult tested insects. Conversely, methomyl and imidacloprid with $\mathrm{LC}_{50}$ values of 300.038 and $355.295 \mathrm{mg} \cdot \mathrm{l}^{-1}$, respectively, were the least toxic to the adults of A. lucorum. The results of bioassays also showed that the oral and residual toxicities of fipronil were the highest amongst the insecticides tested and that fipronil was the most toxic compound for nymphs as well as adults.

\section{Comparison of insecticide toxicity in males and females}

Our results showed that the $\mathrm{LD}_{50}$ values for endosulfan, bifenthrin, chlorpyrifos, carbosulfan, methomyl, fipronil, and imidacloprid were almost always numerically higher for female adults compared to male adults. There were no significant differences, however, between insecticides based on the overlapping confidence limits of $\mathrm{LD}_{50}$ values. The relative toxicity ratio $(R T R)$ values ranged from a low of 1.094- to 1.587-fold, which can be explained by the size difference between males and females. However, the organophosphate insecticide malathion was 1.706-fold more toxic to the male $A$. lucorum than to the female $A$. lucorum. The $\mathrm{LD}_{50}$ value for this organophosphate was sig- nificantly higher for females $\left(\mathrm{LD}_{50}=0.716 \mathrm{mg} \cdot \mathrm{m}^{-2}\right)$ compared to males $\left(\mathrm{LD}_{50}=0.419 \mathrm{mg} \cdot \mathrm{m}^{-2}\right)$ (Table 3).

\section{Selective toxicity between predatory arthropods and Apolygus lucorum}

The toxicity of endosulfan was lowest for C. sinica and P. japonica adults, with $\mathrm{LD}_{50}$ values of 2.482 and $2.181 \mathrm{mg} \cdot \mathrm{m}^{-2}$, respectively. Endosulfan, however, was relatively toxic to the target pests and was safe to two predators according to the selective toxicity ratio (STR) values, which were 5.396- and 4.749-fold, respectively. Thus, endosulfan had the highest selectivity to both $C$. sinica and P. japonica. Two predators were sensitive to fipronil. This insecticide exhibited high levels of insecticidal activity against A. lucorum, with $\mathrm{LD}_{50}$ values of only 0.002 and $0.055 \mathrm{mg} \cdot \mathrm{m}^{-2}$. Fipronil had a higher selectivity for $P$. japonica $(S T R=5.018$-fold , while fipronil had a low selectivity for $C$. sinica $(S T R=$ 0.167 -fold). For another insecticide, bifenthrin, the STR values for P. japonica and C. sinica were 4.220-fold and 0.540fold, respectively, indicating that bifenthrin was also selective for P. japonica. Among the insecticides tested, the STR values for imidacloprid were the lowest, specifically, 0.018fold for $C$. sinica and 0.021 -fold for $P$. japonica. To summarise, based on the STR values for the eight chemicals, endosulfan was relatively safe for C. sinica and P. japonica, which are common predators in Bt cotton fields (Table 4).

Table 3. Lethal concentration (LD) $\left(\mathrm{mg} \cdot \mathrm{m}^{-2}\right)$ data for the contact toxicity of technical insecticides to female and male Apolygus lucorum as determined by the glass-vial bioassay

\begin{tabular}{|c|c|c|c|c|c|c|}
\hline Insecticides & Gender & $N^{\mathrm{a}}$ & $\chi^{2}(\mathrm{df})$ & Slope $\pm S E$ & $\mathrm{LD}_{50}^{\mathrm{b}}(95 \% \mathrm{CL})$ & $R_{T R}^{\mathrm{c}}$ \\
\hline \multirow[t]{2}{*}{ Endosulfan } & female & 240 & $1.92(7)$ & $2.802 \pm 0.236$ & $0.110(0.096-0.126) \mathrm{a}$ & 1.103 \\
\hline & male & 245 & $2.45(7)$ & $2.459 \pm 0.112$ & $0.099(0.088-0.113)$ a & \\
\hline \multirow[t]{2}{*}{ Bifenthrin } & female & 210 & $2.69(6)$ & $1.991 \pm 0.095$ & $0.041(0.037-0.044)$ a & 1.196 \\
\hline & male & 210 & $3.11(6)$ & $2.168 \pm 0.253$ & $0.034(0.027-0.041) \mathrm{a}$ & \\
\hline \multirow[t]{2}{*}{ Chlorpyrifos } & female & 210 & $2.68(6)$ & $2.011 \pm 0.255$ & $0.369(0.303-0.452) \mathrm{a}$ & 1.186 \\
\hline & male & 211 & $3.17(6)$ & $2.207 \pm 0.052$ & $0.312(0.294-0.332)$ a & \\
\hline \multirow[t]{2}{*}{ Malathion } & female & 180 & $2.91(5)$ & $2.932 \pm 0.098$ & $0.716(0.663-0.775) \mathrm{a}$ & 1.706 \\
\hline & male & 185 & $2.76(5)$ & $3.524 \pm 0.141$ & $0.419(0.401-0.438) b$ & \\
\hline \multirow[t]{2}{*}{ Carbosulfan } & female & 210 & $4.17(6)$ & $2.451 \pm 0.586$ & $0.753(0.650-0.874) \mathrm{a}$ & 1.094 \\
\hline & male & 215 & $3.03(6)$ & $2.135 \pm 0.288$ & $0.687(0.634-0.745)$ a & \\
\hline \multirow[t]{2}{*}{ Methomyl } & female & 210 & $2.24(6)$ & $2.158 \pm 0.045$ & $0.061(0.058-0.065) \mathrm{a}$ & 1.263 \\
\hline & male & 180 & $2.79(5)$ & $1.944 \pm 0.092$ & $0.049(0.046-0.053) \mathrm{a}$ & \\
\hline \multirow[t]{2}{*}{ Fipronil } & female & 215 & $3.97(6)$ & $2.454 \pm 0.822$ & $0.019(0.016-0.024) \mathrm{a}$ & 1.199 \\
\hline & male & 240 & $3.72(7)$ & $2.367 \pm 0.142$ & $0.016(0.014-0.017) \mathrm{a}$ & \\
\hline \multirow[t]{2}{*}{ Imidacloprid } & female & 210 & $2.31(6)$ & $2.165 \pm 0.248$ & $45.581(28.545-65.897)$ a & 1.587 \\
\hline & male & 215 & $2.14(6)$ & $2.624 \pm 0.075$ & 28.738 (19.570-42.202) a & \\
\hline
\end{tabular}

atotal number of tested individuals at 5 to 9 concentrations

${ }^{b}$ within columns, data followed by a common letter indicate no significant difference based upon the presence of overlap in the $95 \%$ confidence limits (CL)

crelative toxicity ratio $(R T R)$ determined by comparing the $\mathrm{LD}_{50}$ value for each insecticide in females with the $\mathrm{LD}_{50}$ value in males 
Table 4. Lethal concentration (LD) $\left(\mathrm{mg} \cdot \mathrm{m}^{-2}\right)$ data for the contact toxicity of technical insecticides to Chrysopa sinica/Propylaea japonica as determined by the glass-vial bioassay

\begin{tabular}{|c|c|c|c|c|c|c|c|}
\hline Predators & Insecticides & $N^{\mathrm{a}}$ & $\chi^{2}(\mathrm{df})$ & Slope $\pm S E$ & $\mathrm{LD}_{50} \mathrm{~b}(95 \% \mathrm{CL})$ & $\mathrm{LD}_{50}$ of A. lucorum & $S T R^{c}$ \\
\hline \multirow[t]{8}{*}{ C. sinica } & endosulfan & 180 & $1.87(5)$ & $2.762 \pm 0.294$ & $2.482(1.903-3.395) \mathrm{f}^{*}$ & $0.462(0.287-1.174)$ & 5.396 \\
\hline & bifenthrin & 180 & $1.62(5)$ & $2.774 \pm 0.631$ & $0.071(0.049-0.099) b^{*}$ & $0.132(0.102-0.174)$ & 0.540 \\
\hline & chlorpyrifos & 180 & $1.95(5)$ & $2.858 \pm 0.514$ & $0.055(0.042-0.075) \mathrm{b}^{*}$ & $0.817(0.586-1.249)$ & 0.068 \\
\hline & malathion & 182 & $1.69(5)$ & $2.746 \pm 0.496$ & $0.107(0.087-0.135) c^{*}$ & $0.652(0.431-1.246)$ & 0.165 \\
\hline & carbosulfan & 178 & $2.73(5)$ & $3.614 \pm 0.667$ & $0.667(0.443-1.219) \mathrm{e}$ & $1.365(1.132-1.591)$ & 0.489 \\
\hline & methomyl & 180 & $1.87(5)$ & $2.937 \pm 0.523$ & $0.065(0.054-0.079) \mathrm{b}$ & $0.196(0.071-0.313)$ & 0.343 \\
\hline & fipronil & 180 & $1.71(5)$ & $2.895 \pm 0.623$ & $0.002(0.002-0.005) \mathrm{a}^{*}$ & $0.013(0.009-0.021)$ & 0.167 \\
\hline & imidacloprid & 180 & $1.57(5)$ & $2.982 \pm 0.553$ & $0.243(0.182-0.368) \mathrm{d}^{*}$ & 13.211(12.981-13.455) & 0.018 \\
\hline \multirow[t]{8}{*}{ P. japonica } & endosulfan & 184 & $2.83(5)$ & $2.257 \pm 0.626$ & $2.181(0.662-7.225) \mathrm{e}$ & $0.462(0.287-1.174)$ & 4.749 \\
\hline & bifenthrin & 180 & $2.64(5)$ & $2.449 \pm 0.375$ & $0.553(0.406-0.842) \mathrm{d}^{*}$ & $0.132(0.102-0.174)$ & 4.220 \\
\hline & chlorpyrifos & 182 & $2.35(5)$ & $2.551 \pm 0.387$ & $0.467(0.352-0.665) \mathrm{d}$ & $0.817(0.586-1.249)$ & 0.570 \\
\hline & malathion & 180 & $1.83(5)$ & $2.677 \pm 0.429$ & $0.585(0.429-0.912) \mathrm{d}$ & $0.652(0.431-1.246)$ & 0.898 \\
\hline & carbosulfan & 180 & $1.72(5)$ & $2.618 \pm 0.562$ & $0.228(0.174-0.311) b c^{*}$ & $1.365(1.132-1.591)$ & 0.162 \\
\hline & methomyl & 180 & $3.46(5)$ & $1.771 \pm 0.366$ & $0.169(0.128-0.215) b$ & $0.196(0.071-0.313)$ & 0.819 \\
\hline & fipronil & 180 & $2.41(5)$ & $2.585 \pm 0.550$ & $0.055(0.035-0.077) \mathrm{a}^{*}$ & $0.013(0.009-0.021)$ & 5.018 \\
\hline & imidacloprid & 178 & $2.98(5)$ & $2.021 \pm 0.345$ & $0.273(0.217-0.382) c^{*}$ & 13.211(12.981-13.455) & 0.021 \\
\hline
\end{tabular}

atotal number of tested individuals at 5 to 9 concentrations

${ }^{b}$ within columns, data followed by a common letter indicate no significant difference based upon the presence of overlap in the $95 \%$ confidence limits (CL)

'selective toxicity ratio (STR) estimated by comparing the $\mathrm{LD}_{50}$ value for each insecticide in the predator (C. sinica or P. japonica) with the $\mathrm{LD}_{50}$ value in A. lucorum

*significant difference $(\mathrm{p}<0.05)$ between the $\mathrm{LD}_{50}$ value in the predator and the $\mathrm{LD}_{50}$ value in $A$. lucorum for the same insecticide

\section{Discussion}

Chemical control relying on insecticides with various modes of action is thought to be a potentially effective measure against A. lucorum (Liu et al. 2008; Tan et al. 2012). The key data of our study showed that there were significant differences between the $\mathrm{LD}_{50}$ or $\mathrm{LC}_{50}$ values for the insecticides tested against A. lucorum within each insecticidal class (Tables 1, 2). Many reports have confirmed that fipronil exhibits high toxicity against highly damaging agricultural pests, including cotton plant bugs (Zhang et al. 2009; Zhao and Salgado 2010; Ma et al. 2012). This conclusion, in relation to A. lucorum, is exemplified by the results demonstrating that fipronil had the highest acute oral and contact toxicity to 4th-instar nymphs and adults. It is noteworthy that since the mid-1990s, fipronil has been recommended for the management of another harmful mirid species of cotton in the U.S., Lygus lineolaris (Palisot de Beauvois), and has significantly enhanced the effectiveness of the management of this harmful mirid species (Snodgrass et al. 2008). Neonicotinoids have become an important chemical group for the control of plant-sucking insects (e.g. aphids, thrips, and whiteflies), and act as competitive inhibitors of nicotinic acetylcholine receptors in the central nervous system (Wang et al. 2007; Shi et al. 2011). Chinese farmers have almost exclusively relied on applying imidacloprid or acetamiprid rotated with other conventional insecticides to control A. lucorum in cotton fields, orchards, and tea-planted fields in North China. However, there is no clear reason for doing so, because our results show that imidacloprid is the least toxic agent to A. lucorum out of all of the insecticides tested in this study. We speculate that the most likely reason for the low toxicity of imidacloprid is that its toxicity is temperature dependent (Ma et al. 2012). At a low tested temperature (the tested temperature in this study was $25^{\circ} \mathrm{C}$ ), the toxicity of imidacloprid to A. lucorum was surprisingly much lower than it was at a high temperature (e.g. $35^{\circ} \mathrm{C}$ ), almost resulting in a loss of efficacy. Hence, during the application of imidacloprid for controlling A. lucorum, the influence of temperature on the toxicity of this chemical should be taken into consideration.

The conventional insecticides, namely, organochlorines, pyrethroids, organophosphates, and carbamates, which are most commonly used for the low-cost control of cotton pests, had a certain degree of toxicity to $A$. $l u$ corum. These conventional insecticides, including endo- 
sulfan, bifenthrin, and chlorpyrifos etc. had been recommended previously and have effectively controlled the other mirid species Latrodectus hesperus Knight and L. lineolaris for years (Snodgrass and Scott 2000; Udayagiri et al. 2000). There are few data available on the differences in the susceptibility of A. lucorum to conventional insecticides, which have also been observed in earlier reports by Zhang et al. (2009) and Guo et al. (2010). Unfortunately, conventional insecticides are likely to be more damaging to natural enemies, particularly in fields where survival from the sprays is low (Easterbrook 1997). Additionally, extensive and intensive use of insecticides will likely have adverse effects on human health and the environment and may result in the development of insecticide resistance in abundant target pest populations (Węgorek et al. 2011). Therefore, in these cases, the use of insecticides should be restricted as much as possible by developing new formulation technologies, new pesticide types, and new application methods for pesticides, together with improved pest monitoring, established treatment thresholds, and improved non-chemical control measures.

Our results (Tables 1,2) suggest that various stages of A. lucorum were relatively susceptible to fipronil, bifenthrin, and endosulfan. This information will be useful for A. lucorum control. It seems plausible that the greater toxicity of these insecticides was due to their different sites of action in the nervous system of the targeted insect pest. Fipronil and endosulfan are well-known GABA-gated chloride channel-blocking insecticides, while the target site of bifenthrin is the voltage-sensitive sodium channel (Barčić et al. 2006; Zhao and Salgado 2010; Shi et al. 2012). In addition, aside from its direct (lethal) effect on $\mathrm{A}$. lucorum, studies have demonstrated that exposure to lethal concentrations of pesticides have long-term, adverse effects not only on the individual behavior (e.g. survival, fecundity, and egg hatching) of A. lucorum but also on its population dynamics (Liu et al. 2008; Tan et al. 2012). All of the above information helps assess the value of these insecticides as a control tool for A. lucorum. The information also provides a basis for exercising rational chemical control in Bt cotton fields in China.

In comparison with female A. lucorum, males were sensitive to all of the insecticides tested, and there were differences in their sensitivity to different insecticides (Table 3). Previous studies with different insecticides also showed differential susceptibility between the sexes of tested insects (López et al. 2008; Arthur 2012). It was suggested by Zhang (1988) that females were less sensitive to organophosphates and carbamates than males owing to the lower quantity of acetylcholinesterase in females. We did not find any evidence to suggest that the mechanisms of toxicity of these selected insecticides involved the inhibition of acetylcholinesterase. Acetylcholinesterase is an enzyme that plays a major role in nerve conduction in insects. Thus, the differential sensitivity between the sexes may stem from differences in the physiological state of insects, as measured by body weight (Tan et al. 2012). In all the cases, the female A. lucorum weighed significantly more compared to the males (Men et al. 2008). A similar result was demonstrated by López et al. (2008). They indicated that the higher female $\mathrm{LC}_{50}$ values for insecticides in the cotton fleahopper (Pseudatomoscelis seriatus) were likely a result of the higher body weights of females. Thus, possible physiological mechanisms responsible for the phenomenon remain unknown and require further work. Based on our findings, however, it is noteworthy that the tolerance of females to insecticides may also help magnify the risk of insecticide resistance evolving in A. lucorum as a result of the females' survival, following the spraying of insecticide in fields.

Our studies focused on the lethality of insecticides to C. sinica and P. japonica adults. We have provided important information for fully understanding the relative safety of the tested chemicals to two non-target arthropods in cotton. There were no previous data on this subject available in the literature. In reality, an insecticide's utility increases if it controls A. lucorum while having a minimal impact on beneficial organisms. In our experiment with two predators, the STR values were highest for endosulfan, indicating that endosulfan was safe to C. sinica and P. japonica. Zhu et al. (1998) have previously concluded that endosulfan is also a desirable insecticide for controlling resistant cotton aphids, based on the STR values for endosulfan in P. japonica. Interestingly, fipronil showed the highest toxicity to the two predators, but it was selective for P. japonica only. Moreover, a similar phenomenon was also observed in the bifenthrin treatment. Our results confirm the findings of earlier studies which indicated that fipronil had a mild effect on generalist predators (e.g. ladybird beetles, chrysopids, and spiders) when fibronil was used under field conditions (Kumar et al. 2012; Seagraves and Lundgren 2012). Conversely, imidacloprid had the lowest STR values and was found to be the least selective of the tested compounds with regard to the two generalist predators. The conclusion that the predators are highly susceptible to neonicotinoids, particularly imidacloprid, is also based on observations from other studies (Al-Kherb 2011; Kumar et al. 2012; Seagraves and Lundgren 2012). The above information is disappointing for cotton growers given that neonicotinoids are efficacious against some key piercing-sucking pests of Bt cotton (Tan et al. 2012). An appreciation of the lethal effects of insecticides on two important beneficial arthropods could help in the design of IPM programs with an emphasis on biological control for A. lucorum (Desneux et al. 2007). Meanwhile, to assess the total effect of toxicants on the natural enemies of A. lucorum, a long-term study is needed to evaluate the potential sublethal effects.

Laboratory bioassays are a convenient and useful way for screening a range of insecticides to determine which insecticides should be applied for the chemical control of A. lucorum. The accuracy and usefulness of the bioassays will depend on the correlation of bioassay results with methods that more closely approximate the effects of insecticides used under field conditions (Fitzgerald 2004; Zhang et al. 2009). To sum up, the development of insecticide toxicity curves in our study provides a useful basis for selecting appropriate insecticides to implement scientific chemical control of A. lucorum and minimise the adverse impacts on beneficial arthropods, human health, and the natural environment. Of the insecticides tested in the present study, endosulfan (in reasonable doses), with 
its reduced impact on beneficial arthropods, showed the greatest promise for the control of A. lucorum, followed by fipronil and bifenthrin. Although our bioassays were conducted under relatively controlled conditions, we believe that our results provided valuable insights regarding likely trends. Further work addressing more precise impacts of insecticides on A. lucorum and non-targeted predators, as well as examining rational pest-control strategies, such as insecticide rotations and mixtures, would strengthen our understanding of the IPM of this pest.

\section{Acknowledgements}

We thank two anonymous reviewers for their helpful comments and suggestions on the manuscript. This research was supported by the National Key Technology R\&D Program of China (2012BAD19B05-007), National Natural Science Foundation of China (31572040, 31501651), Natural Science Foundation of Shandong Province (ZR2015CQ017), and the Modern Tea Industry Technology System of Shandong Province.

\section{References}

Abbott W.S. 1925. A method of computing the effectiveness of an insecticide. Journal of Economic Entomology 18 (2): 265-267.

Ahmed M.A.I., Eraky E.-S.A., Mohamed M.F., Soliman A.-A.S. 2015. Potential toxicity assessment of novel selected pesticides against sand termite, Psammotermes hypostoma Desneux workers (Isoptera: Rhinotermitidae) under field conditions in Egypt. Journal of Plant Protection Research 55 (2): 193-197.

Al-Kherb W.A. 2011. Field efficacy of some neonicotinoid insecticides on whitefly Bemisia tabaci (Homoptera: Aleyrodidae) and its natural enemies in cucumber and tomato plants in Al-qassim Region, KSA. Journal of Entomology 8 (5): 429-439.

Arthur F.H. 2012. Lethal and sub-lethal effects from short-term exposure of Rhyzopertha dominica on wheat treated with Storicide II ${ }^{\circledR}$. Journal of Pest Science 85 (2): 261-265.

Barčić J.I., Bažok R., Bezjak S., Čuljak T.G., Barčić J. 2006. Combinations of several insecticides used for integrated control of Colorado potato beetle (Leptinotarsa decemlineata, Say., Coleoptera: Chrysomelidae). Journal of Pest Science 79 (4): 223-232.

Deng S.D., Xu J., Zhang Q.W., Zhou S.W., Xu G.J. 2003. Effect of transgenic Bt cotton on population dynamics of the nontarget pests and natural enemies of pests. Acta Entomologica Sinica 46 (1): 1-5.

Desneux N., Decourtye A., Delpuech J.-M. 2007. The sublethal effects of pesticides on beneficial arthropods. Annual Review of Entomology 52 (1): 81-106.

Easterbrook M.A. 1997. A field assessment of the effects of insecticides on the beneficial fauna of strawberry. Crop Protection 16 (2): 147-152.

Feng H., Jin Y., Li G., Feng H. 2012. Establishment of an artificial diet for successive rearing of Apolygus lucorum (Hemiptera: Miridae). Journal of Economic Entomology 105 (6): 1921-1928.

Fitzgerald J. 2004. Laboratory bioassays and field evaluation of insecticides for the control of Anthonomus rubi, Lygus rugu- lipennis and Chaetosiphon fragaefolii, and effects on beneficial species, in UK strawberry production. Crop Protection 23 (9): 801-809.

Guo T.E., Zhang Z.Q., Zhou C., Liu F., Mu W. 2010. Susceptibilities of Lygus lucorum Meyer-Dür (Hemiptera: Miridae) from five cotton-growing regions in Shandong, China to selected insecticides. Acta Entomologica Sinica 53 (9): 993 1000.

Hardee D.D., Bryan W.W. 1997. Influence of Bacillus thuringiensis-transgenic and nectariless cotton on insect populations with emphasis on the tarnished plant bug (Heteroptera: Miridae). Journal of Economic Entomology 90 (2): 663-668.

Kumar R., Kranthi S., Nitharwal M., Jat S.L., Monga D. 2012. Influence of pesticides and application methods on pest and predatory arthropods associated with cotton. Phytoparasitica 40 (5): 417-424.

Liu Y.Q., Lu Y., Wu K.M., Wyckhuys K.A.G., Xue F.S. 2008. Lethal and sublethal effects of endosulfan on Apolygus lucorum (Hemiptera: Miridae). Journal of Economic Entomology 101 (6): 1805-1810.

Liu Y.Q., Wu K.M., Xue F.S. 2007. [Progress on the studies of Miridae resistance management]. Entomological Journal of East China 16 (2): 141-148. (in Chinese, with English summary)

López J.D., Hoffmann W.C., Latheef M.A., Fritz B.K., Martin D.E., Lan Y. 2008. Adult vial bioassays of insecticidal toxicity against cotton fleahopper, Pseudatomoscelis seriatus (Hemiptera: Miridae). Journal of Pesticide Science 33 (3): 261-265.

Lu Y.H., Liang G.M., Wu K.M. 2007. [Advances in integrated management of cotton mirids]. Plant Protection 33 (6): 1015. (in Chinese, with English summary)

Lu Y.H., Qiu F., Feng H.Q., Li H.B., Yang Z.C., Wyckhuys K.A.G., Wu K.M. 2008a. Species composition and seasonal abundance of pestiferous plant bugs (Hemiptera: Miridae) on Bt cotton in China. Crop Protection 27 (3-5): 465-472.

Lu Y.H., Wu K.M. 2011. Mirid bugs in China: pest status and management strategies. Outlooks on Pest Management 22 (6): 248-252.

Lu Y.H., Wu K.M., Cai X.M., Liu Y.Q. 2008b. [A rearing method for mirids using the green bean, Phaseolus vulgaris in the laboratory]. Acta Phytophylacia Sinica 35 (3): 215-219. (in Chinese, with English summary)

Lu Y.H., Wu K.M., Jiang Y.Y., Guo Y.Y., Desneux N. 2012a. Widespread adoption of Bt cotton and insecticide decrease promotes biocontrol services. Nature 487 (7407): 362-365.

Lu Y.H., Jiao Z., Wu K.M. 2012b. Early season host plants of Apolygus lucorum (Heteroptera: Miridae) in northern China. Journal of Economic Entomology 105 (5): 1603-1611.

Lu Y.H., Wu K.M., Jiang Y.Y., Xia B., Li P., Feng H.Q., Wyckhuys K.A.G., Guo Y.Y. 2010. Mirid bug outbreaks in multiple crops correlated with wide-scale adoption of Bt cotton in China. Science 328 (5982): 1151-1154.

Lu Z.Z., Zalucki M.P., Perkins L.E., Wang D.Y., Wu L.L. 2013. Towards a resistance management strategy for Helicoverpa armigera in Bt-cotton in northwestern China: an assessment of potential refuge crops. Journal of Pest Science 86 (4): 695-703.

Ma Y.H., Gao Z.L., Dang Z.H., Li Y.F., Pan W.L. 2012. Effect of temperature on the toxicity of several insecticides to Apoly- 
gus lucorum (Heteroptera: Miridae). Journal of Pesticide Science 37 (2): 135-139.

Men X.Y., Yu Y., Zhang A.S., Li L.L., Zhang J.T., Ge F. 2008. Life table of the laboratory population of Lygus lucorum MeyerDür (Hemiptera: Miridae) at different temperatures. Acta Entomologica Sinica 51 (11): 1216-1219.

Moens J., Tirry L., De Clercq P. 2012. Susceptibility of cocooned pupae and adults of the parasitoid Microplitis mediator to selected insecticides. Phytoparasitica 40 (1): 5-9.

Pan H., Lu Y., Wyckhuys K.A.G., Wu K. 2013. Preference of a polyphagous mirid bug, Apolygus lucorum (Meyer-Dür) for flowering host plants. PLoS One 8 (7): e68980. DOI: 10.1371/journal.pone.0068980

Planes L., Catalán J., Tena A., Porcuna J.L., Jacas J.A., Izquierdo J., Urbaneja A. 2013. Lethal and sublethal effects of spirotetramat on the mealybug destroyer, Cryptolaemus montrouzieri. Journal of Pest Science 86 (2): 321-327.

Saber M., Abedi Z. 2013. Effects of methoxyfenozide and pyridalyl on the larval ectoparasitoid Habrobracon hebetor. Journal of Pest Science 86 (4): 685-693.

Seagraves M.P., Lundgren J.G. 2012. Effects of neonicitinoid seed treatments on soybean aphid and its natural enemies. Journal of Pest Science 85 (1): 125-132.

Shi X.B., Jiang L.L., Wang H.Y., Qiao K., Wang D., Wang K.Y. 2011. Toxicities and sublethal effects of seven neonicotinoid insecticides on survival, growth and reproduction of imidacloprid-resistant cotton aphid, Aphis gossypii. Pest Management Science 67 (12): 1528-1533.

Shi X.Q., Xiong M.H., Jiang W.H., Wang Z.T., Guo W.C., Xia Z.H., Fu W.J., Li G.Q. 2012. Efficacy of endosulfan and fipronil and joint toxic action of endosulfan mixtures against Leptinotarsa decemlineata (Say). Journal of Pest Science 85 (4): 519-526.

Snodgrass G.L. 1996. Glass-vial bioassay to estimate insecticide resistance in adult tarnished plant bugs (Heteroptera: $\mathrm{Mi}-$ ridae). Journal of Economic Entomology 89 (5): 1053-1059.

Snodgrass G.L., Gore J., Abel C.A., Jackson R. 2008. Predicting field control of tarnished plant bug (Hemiptera: Miridae) populations with pyrethroid insecticides by use of glassvial bioassays. Southwestern Entomologist 33 (3): 181-189.

Snodgrass G.L., Scott W.P. 2000. Seasonal changes in pyrethriod resistance in tarnished plant bug (Heteroptera: Miridae) population during a three-year period in the delta area of Arkansas, Louisiana, and Mississippi. Journal of Economic Entomology 93 (2): 441-446.

Tan Y., Biondi A., Desneux N., Gao X.W. 2012. Assessment of physiological sublethal effects of imidacloprid on the mirid bug Apolygus lucorum (Meyer-Dür). Ecotoxicology 21 (7): 1989-1997.

Udayagiri S., Norton A.P., Welter S.C. 2000. Integrating pesticide effects with inundative biological controli: interpretation of pesticide toxicity curves for Anaphes iole in strawberries. Entomologia Experimentalis et Applicata 95 (1): 87-95.
Wang K.Y., Guo Q.L., Xia X.M., Wang H.Y., Liu T.X. 2007. Resistance of Aphis gossypii (Homoptera: Aphididae) to selected insecticides on cotton from five cotton production regions in Shandong, China. Journal of Pesticide Science 32 (4): 372-378.

Węgorek P., Zamojska J., Mrówczyński M. 2011. High resistance to pyrethroid insecticides in the Polish pollen beetle (Meligethes aeneus F.): the role of oxidative metabolism. Phytoparasitica 39 (1): 43-49.

Wheeler A.G. 2001. Biology of the Plant Bugs (Hemiptera: Miridae): Pests, Predators, Opportunists. Cornell University Press, Ithaca, USA, $528 \mathrm{pp}$.

Wu K.M. 2007. Environmental impact and risk management strategies of Bt cotton commercialization in China. Chinese Journal of Agricultural Biotechnology 4 (2): 93-97.

Wu K.M., Li W., Feng H.Q., Guo Y.Y. 2002. Seasonal abundance of the mirids, Lygus lucorum and Adelphocoris spp. (Hemiptera: Miridae) on Bt cotton in northern China. Crop Protection 21 (10): 997-1002.

Wu K.M., Lu Y.H., Feng H.Q., Jiang Y.Y., Zhao J.Z. 2008. Suppression of cotton bollworm in multiple crops in China in areas with Bt toxin-containing cotton. Science 321 (5896): 1676-1678.

Xue M., Li Q. 2002. Studies on selective toxicity of six insecticides between green peach aphid and ladybirds. Insect Science 9 (2): 17-22.

Zhang L., Lu Y., Liang G. 2013. A method for field assessment of plant injury elicited by the salivary proteins of Apolygus lucorum. Entomologia Experimentalis et Applicata 149 (3): 292-297.

Zhang Y.X., Cao Y.P., Bai L.X., Cao C.Y. 1986. [Plant bug damage on cotton in different growing stages and the threshold for control]. Acta Phytophylacica Sinica 13 (2): 73-78. (in Chinese, with English summary)

Zhang Z.B. 1988. Toxicity Determination of Insecticides: Principle, Method and Application. Science Press, Beijing, China, $367 \mathrm{pp}$.

Zhang Z.Q., Guo T.E., Wang W., Liu F., Mu W. 2009. Assessment of relative toxicity of insecticides to the green plant bug, Lygus lucorum Meyer-Dür (Hemiptera: Miridae), by two different bioassay methods. Acta Entomologica Sinica 52 (9): 967-973.

Zhao S.H. 2000. [Plant Chemical Protection]. p. 250-253. China Agriculture Press, Beijing, China, 337 pp. (in Chinese)

Zhao X., Salgado V.L. 2010. The role of GABA and glutamate receptors in susceptibility and resistance to chloride channel blocker insecticides. Pesticide Biochemistry and Physiology 97 (2): 153-160.

Zhu F.X., Wang J.X., Liu F., Mu W., Zhang X. 1998. Studies on insecticide susceptibility of lady birds. Acta Entomologica Sinica 41 (4): 359-365. 